\title{
Effectiveness of a Serogroup B and C Meningococcal Vaccine Developed in Cuba
}

\author{
Rolando F. Ochoa-Azze MD PhD, Luis García-Imía PhD, Vicente Vérez-Bencomo PhD
}

\begin{abstract}
INTRODUCTION Serogroup B meningococcal outer membrane vesicle vaccines have been effective against vaccine-type strains, but their effectiveness against heterologous strains has been controversial. The Cuban VA-MENGOC-BC vaccine is of this type, but also includes meningococcus $C$ capsular polysaccharide.
\end{abstract}

OBJECTIVES Assess the effectiveness of VA-MENGOC-BC in reducing meningococcal disease caused by homologous or heterologous serogroup $B$ strains and its serological effectiveness against meningococcus $\mathrm{C}$.

METHODS A review of studies of VA-MENGOC-BC's application in Cuba, Brazil, Uruguay and Colombia was carried out to examine the vaccine's effectiveness in reducing meningococcal disease during serogroup B outbreaks. Serological effectiveness against serogroup $\mathrm{C}$ determined in these studies (indicated by bactericidal antibody titers before and after vaccination) was also analyzed.

RESULTS VA-MENGOC-BC's effectiveness against homologous serogroup B strains has consistently been greater than $80 \%$ in

\section{INTRODUCTION}

Meningococcal disease is an important global public health concern because of high rates of serious sequelae and mortality. It is endemic worldwide, and outbreaks and epidemics have occurred in all continents, most caused by 5 (A, B, C, Y and W135) of the 13 meningococcal serogroups.[1-6]

Since the introduction of polysaccharide vaccines against serogroups A, C, Y and W135, serogroup B has emerged as the most important cause of meningococcal disease in the Americas, Europe, as well as in Australia and New Zealand.[1,6,7] Effective overall protection against meningococcal disease cannot be achieved without routine use of vaccines against Neisseria meningitidis $(\mathrm{Nm})$ serogroup $\mathrm{B}$.

The serogroup B capsule elicits a poor immunogenic response because its structural similarity to human tissue leads to immunological tolerance. Concerns about autoimmunity have therefore shifted research attention to subcapsular antigens. Several subcapsular proteins have been studied, but vaccines based on outer membrane vesicles (OMV) have been the most widely used.[1-3,8]

Protection induced by serogroup B OMV vaccines has been discussed in various scientific fora. Many researchers believe that

IMPORTANCE The article assesses and synthesizes available evidence regarding the effectiveness of the world's first vaccine effective against Neisseria meningitidis type $\mathrm{B}$, Cuba's VA-MENGOC-BC. all age groups. Effectiveness in heterologous contexts was also above $80 \%$ in individuals aged $>4$ years. Lower effectiveness in heterologous contexts was found in Brazilian children aged $<2$ years, although still $>50 \%$. Effectiveness increased when assessed based on mortality rates, as well as in cases of clinically severe meningococcal disease. The carrier-state pattern was modified after vaccination with reduction of hypervirulent lineages. Some $60 \%$ of infants (aged $<1$ year) attained protective bactericidal antibody titers against serogroup $\mathrm{C}$. Higher protection rates were achieved in older children.

CONCLUSIONS In addition to prevention of meningococcal disease caused by homologous serogroup B strains, VA-MENGOC-BC should be considered for heterologous contexts. It is protective against serogroup $C$ in all age groups.

KEYWORDS Neisseria meningitidis, meningococcal disease, meningococcal vaccines, serogroup $B$ meningococcus, serogroup $C$ meningococcus, immunogenicity, bacterial outer membrane proteins, heterologous effects of vaccines, acellular vaccines, Cuba these vaccines' effectiveness is limited to specific strains (thus describing them as "tailor-made" vaccines), concluding that new vaccine generations are required to ensure broad cross-reactivity, such as those that include recombinant outer membrane proteins (OMP).[1,3,8-10]

VA-MENGOC-BC is a bivalent vaccine based on $\mathrm{Nm}$ serogroup $B$ OMVs and the capsular polysaccharide of $\mathrm{Nm}$ serogroup $\mathrm{C}$ attached to OMP.[2,3] It was developed by Cuba's Finlay Vaccine Institute in Havana in the 1980s and has been extensively used in several countries. The US CDC acknowledged that it was available commercially (but not in the USA) and had been used to control epidemics in South America.[11] However, the vaccine's effectiveness against heterologous serogroup B strains (different phenotype) is controversial, since outside Cuba, it has been used in countries where circulating strains differ from the original strain for which it was developed.[1-3]

VA-MENGOC-BC OMVs are obtained from a hypervirulent strain $(B: 4: P 1.19,15)$ that caused an extensive epidemic in Cuba in the 1980 s, when incidence rose as high as 14.4 per 100,000 population overall and 120 per 100,000 among infants.[2] Conceptually, it could be considered a tailor-made vaccine, since the $B: 4: P 1.19,15$ strain caused the majority of cases. From the beginning, however, vaccine researchers addressed the need for cross-reactive antigen expression to induce protection against heterologous strains (not just homologous ones) for vaccine strain selection and development of production methods.[2,12]

More than one hundred proteins have been detected. A bioinformatics analysis of known components resulted in identification of 31 predicted OMPs. The contribution of major proteins 
(Por A, Por B, Opa, OpcA, RmpM, FetA) to total protein content is $<65 \%$. Vesicles are especially lacking in Por $A,<20 \%$. Conserved proteins (NadA, fHbp, NMB0088, NMB1796, NMB0928) and other important minor proteins (Tbp, NspA, FbpA, HrpA, PilQ, ATP syntethases, bacterioferritins, heat shock proteins and ribosomal proteins, among others) have also been identified.[12-14]

A study published in 2014 by University of Southampton (UK) researchers and GlaxoSmithKline Pharmaceuticals identified novel antigens in VA-MENGOC-BC OMVs, such as exopolyphosphatase and gamma-glutamyltranspeptidase enzymes, and a putative cell-binding factor protein. They also demonstrated that VA-MENGOC-BC induces widely crossreactive bactericidal antibodies.[15]

In this paper, VA-MENGOC-BC effectiveness in reducing meningococcal disease caused by homologous and/or heterologous serogroup B strains was analyzed by age group, as was its serological effectiveness against meningococcus $\mathrm{C}$.

\section{METHODS}

Study design We reviewed results from all published postmarketing studies on VA-MENGOC-BC application in different epidemiological contexts, as well as from the phase III clinical trial in Cuba, to integrate results and derive conclusions on the vaccine's effectiveness. Effectiveness against serogroup B meningococcal disease was defined as the degree of protection attributable to the vaccine when administered under field conditions.[16] VA-MENGOC-BC's serological effectiveness against $\mathrm{Nm}$ serogroups $\mathrm{B}$ and $\mathrm{C}$ was defined by bactericidal antibody titers.

Data sources Scientific papers on VA-MENGOC-BC composition and vaccine efficacy from the Cuban prelicensure phase III clinical trial were reviewed, as were postmarketing observational studies on VA-MENGOC-BC application in Cuba, Brazil, Colombia and Uruguay. The phase III efficacy trial was designed to assess whether VA-MENGOC-BC produced the expected results under ideal circumstances, that is, in a randomized, double-blind, placebo-controlled trial based on a clinical disease endpoint.

We reviewed analytical observational studies (case-control and cohort studies) performed in Cuba, Brazil and Colombia that assessed effectiveness against serogroup B, and studies in Cuba and Uruguay that assessed the impact of vaccination on meningococcal disease burden. Serological effectiveness against serogroups $\mathrm{B}$ and $\mathrm{C}$, and $\mathrm{Nm}$ strains isolated from patients with meningococcal disease and carriers was also investigated in postmarketing studies.

Study variables Age: grouped by $<2 ; 2-4 ;<4$, $>4$ years. $\mathrm{Nm}$ serogroup B strains: Homologous strains of $\mathrm{Nm}$ serogroup $B$ are those similar to vaccine-type strains. Heterologous strains are meningococcal B strains with different phenotypes from the vaccine strain. Bactericidal antibody levels: Seroconversion was defined as a $\geq 4$-fold increase from baseline in titers of antibodies against serogroups $B$ and $C$. Seroprotection was defined as bactericidal titers $\geq 1: 4$ for serogroup $B$ and $\geq 1: 8$ for serogroup C. When whole-blood assay was used, seroprotection against serogroup C was defined as $>50 \%$ killing of meningococci inoculated into whole blood.[3,10]
Data collection and analysis VA-MENGOC-BC's protective effectiveness against homologous and heterologous serogroup $B$ strains was assessed in case-control and cohort studies carried out in Cuba, Brazil and Colombia. Vaccine effectiveness was assessed by age group, taking age four years as the primary breaking point, with additional analyses, when data were available, of groups aged less than two years and two to four years. Bactericidal titers against serogroup B were analyzed before vaccination and one month after the second dose.

Case-control studies compared rates of vaccinated and unvaccinated individuals with meningococcal disease (cases) versus rates of vaccinated and unvaccinated individuals without disease (controls) from the same population. Cohort studies compared rates of meningococcal disease in vaccinated and unvaccinated persons from the same population. The main variable of interest was effectiveness in reducing risk of meningococcal disease, which was reported as odds ratios (OR) in case-control studies and relative risk (RR) in cohort studies; effectiveness was estimated as (1-OR) x 100 or $(1-R R) \times 100$, respectively.

Vaccination impact on meningococcal disease burden in Cuba and Uruguay was assessed taking into account incidence rates of meningococcal disease before and after introducing vaccination. In Uruguay, vaccination effectiveness was calculated by the following formula: $V E=(P-C) /[P(1-C)] \times 100$, where $P$ is the proportion of the population vaccinated and $\mathrm{C}$ the proportion of cases among vaccinees.[16]

Phenotypic and genetic structures of $\mathrm{Nm}$ populations in Cuban patients and carriers were analyzed during pre- and postvaccination periods. Phenotypic characterization was also carried out of $\mathrm{Nm}$ strains in Uruguayan, Colombian and Brazilian patients.

Serological effectiveness against $\mathrm{Nm}$ serogroup $\mathrm{C}$ was assessed by means of serum bactericidal antibody assay (gold standard for meningococcal polysaccharide vaccines) or whole blood assay. Bactericidal activity against the ATCC C11 strain was assessed in postmarketing studies a month after finishing the 2-dose vaccination schedule (with an interval of $6-8$ weeks). It was also assessed a year post vaccination (with 3 consecutive doses at ages 3, 5 and 7 months).

Effectiveness against meningococcal disease caused by homologous or heterologous strains of $\mathrm{Nm}$ serogroup $\mathrm{B}$ in children aged $<2$ years, $2-4$ years, and $>4$ years was compared using the Kruskal-Wallis test, with $95 \%$ confidence intervals usually estimated for measures of effect. Analyses were performed using Statgraphics Plus for Windows v. 3.1 (Statistical Graphics Corporation, USA).

Ethics The Finlay Vaccine Institute's scientific and ethics committees approved the study (code: 002-10-03-2017). Data were collected from published papers and no patient files or electronic medical records were accessed at any stage.

\section{RESULTS}

Vaccination impact on meningococcal disease in Cuba In 1987, a Phase III efficacy trial of VA-MENGOC-BC was conducted. 
It was a controlled, double-blind, randomized trial involving 106,251 boarding school students, aged 10-16 years, using a 2-dose schedule with a 6-8-week interval. This 16-month trial was carried out in the 7 Cuban provinces with highest meningitis incidence. Estimated efficacy was $83 \%(\mathrm{Cl} 44 \%-93 \%)$. A similar point estimate of $81 \%$ was achieved in a cohort study performed in children aged $<4$ years $(886,148$ children, $85 \%$ of whom were vaccinated).[2,3,12]

Following VA-MENGOC-BC's study and subsequent approval by national regulatory authorities, Cuba's Ministry of Public Health (MINSAP) used a two-stage strategy to control meningococcal disease. First, a nationwide mass vaccination campaign was launched to curb increasing incidence. The 1989-1990 campaign targeted the highest-risk population (aged 3 months to 24 years), reaching more than 3 million people, for 95\% coverage. The second stage, still ongoing, began in 1991 with VA-MENGOCBC's inclusion in the National Immunization Program (PNI), using a two-dose schedule (first dose at age three months, second at five months), to protect children born after the mass campaign and prevent further epidemics. VA-MENGOC-BC has also been used in other age groups.[2,3,12]

The strategy has succeeded in reducing overall incidence to 0.1 per 100,000 population in recent years (from 14.4 per 100,000 at the height of the epidemic in 1983-1984). Vaccine effectiveness ranged from $80 \%$ to $100 \%$ in infants (aged $<1$ year), children, adolescents and adults. Mean effectiveness in infants was $84 \%$ between 1997 and 2008 , and reached $93 \%$ in preschool children.[2,3,12,17]

Phenotypic and genetic structure of $\mathrm{Nm}$ populations in Cuba before and after vaccination Phenotypic characterization of strains isolated in carriers during epidemic and postepidemic stages is important to assess the role of vaccination as an intervention. Martínez characterized $\mathrm{Nm}$ strains for 20 years and showed that during the epidemic stage in Cuba, serogroup B (67.6\%), serotype $4(70.5 \%)$ and subtype $\mathrm{P} 1.19,15(61.9 \%)$ predominated, and during the postvaccination period, nonserotypable (NT) $(70.8 \%)$, nonserosubtypable (NST) (34.4\%) and nonserogroupable strains (NG) $(79.7 \%)$ were more frequently found. Thus, the predominant phenotype during the epidemic was B:4:P1.19,15, which was favorably modified in the postvaccination period to phenotype NG:NT:P1.NST.[18]

It is also important to examine, using new tools of molecular biology, the impact of vaccine application on strain distribution in patients and carriers in pre- and postvaccination periods. To that end, Climent isolated strains from 12 clonal complexes in Cuba. The main strain that caused the 1980s' outbreak belonged to the ST32 complex (58.6\% of isolates). VA-MENGOC-BC was found to be effective not only against ST-32 complex, but also ST-41/44, ST-8 and ST-11, among others. Furthermore, the carrier-state pattern was modified, with reduction of hypervirulent lineages. The ST-53 complex, common in asymptomatic carriers, became predominant. [19] A similar conclusion was reported in Climent's study, in which experts from Oxford University (UK) also participated.[20]

VA-MENGOC-BC's effectiveness for controlling serogroup B outbreaks in Brazil and Colombia VA-MENGOC-BC has been widely used to control serogroup $B$ outbreaks in various countries with epidemiological profiles different from Cuba's, in many cases with wide circulation of heterologous strains.
In Brazil, de Moraes performed an ambispective case-control study to estimate VA-MENGOC-BC effectiveness against meningococcal disease in children aged 3 months to 6 years at the beginning of the 1990s: 112 cases and 409 controls were assessed. Only positive or probable cases of serogroup B meningococcal disease were analyzed.[21]

Most cases (83\%) were confirmed by isolation of $\mathrm{Nm}$ serogroup B from cerebrospinal fluid. Effectiveness was $73 \%$ for children aged $>4$ years; $53 \%$ in children aged $2-4$ years, and $5 \%$ in those aged $<2$ years. [21] However, the authors identified biases in selection of cases and controls in their research, which could lead to underestimates of degree of protection, mainly in the retrospective arm. Sources of selection bias were the low vaccination coverage estimated in this arm, as well as the small proportion (17\%) of patients reported with meningococcal disease who met diagnostic criteria for study enrollment: identification of $\mathrm{Nm}$ by culture or antigen detection. On the other hand, for the prospective arm, estimated effectiveness was $55 \%$ in children aged <2 years.[21] Meningococcus strains different from the vaccine-type strain were responsible for about $60 \%$ of cases of meningococcal disease in all age groups, suggesting that the vaccine does provide some protection against strains other than the vaccine type.[21] Table 1 shows the great diversity of strains causing disease in the unvaccinated control group.

Table 1: Serotype and subtype classification of Neisseria meningitidis serogroup isolates, Sao Paulo, Brazil, June 1990-June 1991[21]

\begin{tabular}{|l|r|}
\hline Serotype:subtype & \multicolumn{1}{|c|}{$\mathbf{n}(\%)$} \\
\hline B:4:P1.15 & $39(41.9)$ \\
\hline B:4:P1.NST & $16(17.2)$ \\
\hline B:NT:P1.NST & $7(7.5)$ \\
\hline B:8:P1.NST & $4(4.3)$ \\
\hline B:NT:P1.15 & $3(3.2)$ \\
\hline B:2b:P1.NST & $2(2.2)$ \\
\hline B:15:P1.15 & $2(2.2)$ \\
\hline B:2b:P1.2 & $1(1.1)$ \\
\hline B:4:P1.2 & $1(1.1)$ \\
\hline B:8:P1.15 & $1(1.1)$ \\
\hline B:15:P1.NST & $1(1.1)$ \\
\hline Unknown & $16(17.2)$ \\
\hline Total & $93(100.0)$ \\
\hline
\end{tabular}

NT: nonserotypable NST: nonserosubtypable

However, other analytical observational studies conducted in Brazil during those years showed greater effectiveness. Cases of meningococcal disease were defined by presence of one or more of the following criteria: a) $\mathrm{Nm}$ isolation, b) meningococcal antigens demonstrated by immunological tests, c) gram-negative diplococci identified by gram staining of cerebrospinal fluid, d) patients with a clinical picture compatible with meningococcal disease.[22,23]

In Rio de Janeiro, Noronha's retrospective case-control study in children aged 6 months to 9 years (275 cases, 279 controls) demonstrated high effectiveness in preventing meningococcal disease in children aged $>2$ years.[22] Effectiveness was lower in younger children, but still higher than reported by de Moraes (Table 2).[21] 
Table 2: VA-MENGOC-BC's effectiveness in analytical observational studies of Cuban, Brazilian and Colombian children

\begin{tabular}{|c|c|c|c|}
\hline Location (Date) & Age group & Study type & $\begin{array}{l}\text { Age-specific } \\
\text { effectiveness } \\
\text { Age group, \% }\end{array}$ \\
\hline $\begin{array}{l}14 \text { Provinces/Cuba } \\
(1989-1994)[3,12]\end{array}$ & 3 months -4 years & Case-control & All, 81 \\
\hline $\begin{array}{l}\text { Santa Catarina, Brazil } \\
(1990-1992)^{\mathrm{a}}[23]\end{array}$ & 3 months -7 years & Cohort & $\begin{array}{r}<2 \text { years, } 55 \\
2-4 \text { years, } 62 \\
<4 \text { years, } 59 \\
>4 \text { years, } 78\end{array}$ \\
\hline $\begin{array}{l}\text { Rio de Janeiro, Brazil } \\
(1990-1992)^{b}[22]\end{array}$ & 6 months -9 years & Case-control & $\begin{array}{r}<2 \text { years, } 53 \\
2-4 \text { years, } 77 \\
<4 \text { years, } 64 \\
>4 \text { years, } 80\end{array}$ \\
\hline $\begin{array}{l}\text { Antioquia, Colombia } \\
(1991-1994)[24]\end{array}$ & 3 months -4 years & Cohort & All, 98 \\
\hline
\end{tabular}

${ }^{a}$ cases confirmed as meningococcal disease by laboratory tests

${ }^{b}$ cases of meningococcal disease diagnosed by laboratory or clinical criteria

Noronha's research revealed effectiveness against confirmed serogroup B strains slightly lower than effectiveness for cases defined by all criteria in children aged $<4$ years. It was $69 \%$ in children aged $2-4$ years and $47 \%$ in children aged $<2$ years old. Vaccine-induced protection reached $67 \%(28 \%-85 \%)$ in children aged $<2$ years with severe clinical symptoms.[22]

In the Brazilian state of Santa Catarina, Costa carried out a retrospective cohort study in children aged 3 months to 7 years (400,482 vaccinated children; 89,610 unvaccinated).[23] The reported effectiveness against laboratory confirmed cases of meningococcal infections was similar to the effectiveness found in Rio de Janeiro (Table 2).[22] Effectiveness increased when analysis was restricted to cases that could be classified as $\mathrm{Nm}$ serogroup $\mathrm{B}, 66 \%(\mathrm{Cl} 5 \%-89 \%)$ in children aged 3 months to 4 years and $88 \%(\mathrm{Cl} 54 \%-97 \%)$ in those aged $>4$ years. [23] Effectiveness in children aged $<4$ years reached $68 \%(\mathrm{Cl}$ $51 \%-79 \%$ ) in cases defined by all criteria; specific data were not available for age groups $2-4$ and $<2$ years. On the other hand, when effectiveness assessment was based on mortality rates, it rose to $76 \%$ in the younger children $(\mathrm{Cl} 41 \%-91 \%)$.[23] states, including those referred to here, it reported effectiveness against serogroup B as $72 \%(\mathrm{Cl} 63 \%-80 \%)$ in children aged 6-83 months.[25] The effectiveness found in Brazil is high, especially considering the country's geographical and epidemiological characteristics. The great diversity of meningococcal serosubtypes supports the contention that VA-MENGOC-BC induced crossreactive protection in the age groups assessed.

VA-MENGOC-BC was also used in Colombia during an epidemic in Itaguí, Antioquia, in children aged 3 months to 4 years, in which effectiveness was assessed by examining laboratory-confirmed cases of meningococcal disease in a cohort of 16,762 children (92\% vaccinated). The effectiveness calculated by different methods was $>98 \%$, exceeding the effectiveness estimates of Cuban and Brazilian researchers.[24] These results are important, given that this age group is the most vulnerable and not fully mature immunologically. Although the strains responsible for the outbreak were not precisely determined in the study, both the vaccine strain and the heterologous B:8:P1.NST strain were isolated.[24,26]

VA-MENGOC-BC's impact on a meningococcal disease outbreak in Uruguay The vaccine was used to control a serogroup B meningococcal disease outbreak in Uruguayan children and adolescents aged 4-19 years, the most affected group. Incidence and mortality rates in Canelones Department dropped dramatically after vaccination. Incidence decreased from 7.4 per 100,000 in the epidemic period, to 0 after vaccination in that age group.[27] While the vaccine serosubtype prevailed in the most severe cases, other strains causing meningococcal disease were detected in unvaccinated individuals (Table 3).

In Montevideo Department, incidence declined slightly in the group aged 4-19 years: from 4.6 per 100,000 in the epidemic period, to 3.4 per 100,000 after vaccination.[27] Heterologous strains were isolated in most patients with meningococcal disease (83.9\%) during the epidemic period (Table 4).

In Canelones Department, estimated vaccination coverage was $81 \%$. Meningococcal disease was not detected in vaccinees during the postvaccination period. Vaccination coverage was slightly low-
In Santa Catarina, only a small proportion of cases were serogrouped. In Rio de Janeiro, $57 \%$ of patients enrolled were serogroup $B$, but only $6 \%$ were serotypable or serosubtypable. Although the circulating strains were not specified in these studies, they were likely similar to those isolated in Sao Paulo, with wide circulation of heterologous strains.[23,25]

When Brazil's Ministry of Health assessed the impact of vaccination with VAMENGOC-BC in 6 Brazilian
Table 3: Serotypes and subtypes of Neisseria meningitidis serogroup B isolates, Canelones, Uruguay, April 2000-March 2003[27]

\begin{tabular}{|c|c|c|c|c|}
\hline Serotype:subtype & $\begin{array}{c}\text { Pre-epidemic period } \\
\text { n (\%) }\end{array}$ & $\begin{array}{c}\text { Epidemic period } \\
\mathbf{n}(\%)\end{array}$ & $\begin{array}{c}\text { Prevaccination Total } \\
\mathbf{n}(\%)\end{array}$ & $\begin{array}{c}\text { Postvaccination period }^{*} \\
\text { n (\%) }\end{array}$ \\
\hline $\mathrm{B}: 4,7: \mathrm{P} 1.15,19$ & $3(43)$ & $7(47)$ & $10(46)$ & $3(38)$ \\
\hline $\mathrm{B}: 4,7: \mathrm{P} 1 . \mathrm{NST}$ & & $1(7)$ & $1(5)$ & \\
\hline $\mathrm{B}: 4: P 1.14$ & & & & $1(13)$ \\
\hline B:19:P1.NST & & $1(7)$ & $1(5)$ & \\
\hline B:19:P1.14 & $1(14)$ & & $1(5)$ & \\
\hline B:19,14:P1.17,1 & $1(14)$ & $1(7)$ & $2(9)$ & \\
\hline B:15:P1.16 & & $2(13)$ & $2(9)$ & \\
\hline $\mathrm{B}: 15: \mathrm{P} 1.7,16$ & & & & $1(13)$ \\
\hline B:2b:P1.10 & $1(14)$ & & $1(5)$ & \\
\hline B:NT:P1.5,2 & & & & $1(13)$ \\
\hline B:1:P1.NST & & & & $1(13)$ \\
\hline B:1:P1.9 & $1(14)$ & & $1(5)$ & \\
\hline Not classified & & $3(20)$ & $3(14)$ & $1(13)$ \\
\hline Total & $7(100)$ & $15(100)$ & $22(100)$ & $8(100)$ \\
\hline
\end{tabular}

*cases identified in the postvaccination period were not in the vaccinated age groups

NT: nonserotypable NST: nonserosubtypable 
Table 4: Serotype and subtype classification of Neisseria meningitidis serogroup B isolates, Montevideo, Uruguay, April 2000-March 2003[27]

\begin{tabular}{|c|c|c|c|c|}
\hline Serotype:subtype & $\begin{array}{l}\text { Pre-epidemic period } \\
\text { n (\%) }\end{array}$ & \begin{tabular}{|c|} 
Epidemic period \\
$\mathrm{n}(\%)$
\end{tabular} & $\begin{array}{c}\text { Prevaccination Total } \\
\text { n (\%) }\end{array}$ & $\begin{array}{c}\text { Postvaccination period } \\
\text { n (\%) }\end{array}$ \\
\hline$B: 4,7: P 1.15,19$ & $4(20)$ & $5(16)$ & $9(18)$ & $4(17)$ \\
\hline $\mathrm{B}: 4,7: \mathrm{P} 1.22$ & $2(10)$ & $2(6)$ & $4(8)$ & \\
\hline $\mathrm{B}: 4: P 1.4$ & & $3(10)$ & $3(6)$ & $2(8)$ \\
\hline B:19:P1.16 & & & & $1(4)$ \\
\hline $\mathrm{B}: 4,7: \mathrm{P} 1.7,1$ & & $2(6)$ & $2(4)$ & $1(4)$ \\
\hline B:4,7:P1.NST & $1(5)$ & & $1(2)$ & $1(4)$ \\
\hline B:4:P1.NST & & & & $2(8)$ \\
\hline B:4,10:P1.NST & & $1(3)$ & $1(2)$ & \\
\hline B:19,14:P1.10 & $1(5)$ & & $1(2)$ & \\
\hline B:19,8,7:P1.19 & $2(20)$ & $1(3)$ & $3(6)$ & \\
\hline B:19,1:P1.NST & $2(20)$ & & $2(4)$ & \\
\hline B:19,7:P1.NST & & $1(3)$ & $1(2)$ & \\
\hline B:15:P1.16 & $1(5)$ & $2(6)$ & $3(6)$ & $6(25)$ \\
\hline $\mathrm{B}: 15: \mathrm{P} 1.14$ & & $2(6)$ & $2(4)$ & \\
\hline B:15:P1.NST & & $1(3)$ & $1(2)$ & $1(4)$ \\
\hline $\mathrm{B}: 14,14: \mathrm{P} 1.1,7$ & $1(5)$ & $1(3)$ & $2(4)$ & \\
\hline B:1:P1.NST & $1(5)$ & $3(10)$ & $4(8)$ & $1(4)$ \\
\hline B:NT:P1.NST & $5(25)$ & $5(16)$ & $10(20)$ & $5(21)$ \\
\hline B:NT:P1.14 & & $2(6)$ & $2(4)$ & \\
\hline Total & $20(100)$ & $31(100)$ & $51(100)$ & $24(100)$ \\
\hline
\end{tabular}

NT: nonserotypable NST: nonserosubtypable

er $(73 \%)$ in Montevideo. Most cases $(75 \%)$ were detected in individuals who had not received the two scheduled VA-MENGOC-BC doses. Furthermore, a significant mortality reduction was observed in the vaccinated group, which has also been observed in other studies. In the postvaccination period, disease incidence increased in persons aged $>20$ years, an unvaccinated age group, indicating that outbreak strains continued circulating.[27]

Although the authors did not report vaccine effectiveness,[27] it can be estimated at $88 \%$ in Montevideo and $100 \%$ in Canelones, using Orenstein's formula.[16] Since most strains isolated in Montevideo were heterologous, we can infer that vaccine protection is not strictly limited to the vaccine strain.

Serum bactericidal antibody titers against serogroup B Bactericidal activity against serogroup B was not assessed in most analytical observational studies, except for the Colombian cohort study. Seroconversion in a subsample of 213 children was $84 \%$ (Cl 72\%-96\%), higher than reported in prelicensure clinical trials $(\mathrm{Cl} 50 \%-78 \%)$, but lower than effectiveness based on clinical endpoint (98\%). Seroprotection, defined as bactericidal antibody titers $\geq 1: 4$, was not analyzed in this study.

However, all seroconverted individuals were obviously seroprotected, because seroconversion was defined as greater than fourfold increase in antibody titers from baseline.[24,26] It is worth noting that seroconversion rates observed in phase II clinical trials found were lower than efficacy in phase III clinical trials (that is, seroconversion underestimated the degree of protection conferred).[2,12]

Statistical analysis of VA-MENGOC-BC's effectiveness against homologous and heterologous serogroup B strains Overall, the vaccine's effectiveness against homologous strains has been
$>80 \%$ in all age groups, with no significant differences by age $(p=0.772)$. Its effectiveness in heterologous contexts was similar to the one found against homologous strains in individuals aged $>4$ years $(p=0.434)$. Lower effectiveness was detected in Brazilian children aged $<2$ years; although there was no statistically significant difference by age in heterologous contexts ( $p=0.067$ ). [21-23,25]

The cohort of Colombian children aged $<4$ years was not subdivided, but it is unlikely that differences would have been found, because overall effectiveness was so high (98\%).[24]

VA-MENGOC-BC's serological effectiveness against $\mathrm{Nm}$ serogroup C This vaccine has only been used to control outbreaks of serogroup B meningococcal disease, so clinical effectiveness against serogroup $C$ has not been estimated. However, bactericidal activity against $\mathrm{Nm}$ serogroup $\mathrm{C}$ has been assessed. High seroconversion and seroprotection rates have been detected in all age groups against this serogroup (Table 5).

Morley's study of Cuban infants assessed seroprotection rates by whole-blood assay. Seroprotection against serogroup C was $60 \%$ a year after vaccination with doses at ages 3,5 and 7 months. [28] Mean seroprotection in young Cuban adults 12 years after vaccination and with high background levels was $66 \%$, higher than seroconversion.[29]

Notably, high seroconversion rates were found in Colombian toddlers and preschool children $(88 \%)$; most seroconverted

Table 5: Bactericidal activity induced by VA-MENGOC-BC against Neisseria meningitidis serogroup $C$ in infants, children, teenagers and young adults

\begin{tabular}{l|r|r|r|}
\hline Country (year) & $\begin{array}{r}\text { Age group } \\
\text { (years) }\end{array}$ & $\begin{array}{c}\text { Seroconversion } \\
(\%)\end{array}$ & $\begin{array}{c}\text { Seroprotection } \\
(\%)\end{array}$ \\
\hline Colombia (1995) $[30]$ & $1-5$ & 88 & 86 \\
\hline Belarus, Ukraine, & $5-11$ & 74 & na \\
Russia (1995) ${ }^{\mathrm{a}}[2]$ & $12-18$ & 67 & na \\
\hline Iceland $(1998)^{\mathrm{a}}[2]$ & $20-22$ & 96 & na \\
\hline Cuba $(2001)^{\mathrm{b}}[28]$ & $<1$ & na & 60 \\
\hline Cuba $(2004)^{\mathrm{a}}[29]$ & $15-18$ & 58 & 66
\end{tabular}

aBactericidal antibody levels measured by serum bactericidal antibody assay

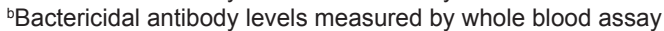

na: data not available

Seroconversion: (bactericidal antibody titers postvaccination / bactericidal antibody titers prevaccination) $\geq 4$

Seroprotection (serum bactericidal antibody assay): bactericidal antibody titers $\geq 1: 8$ Seroprotection (whole blood assay): $>50 \%$ killing of meningococci inoculated in whole blood 
children had bactericidal titers $\geq 1: 8$, and were therefore protected against serogroup C.[30]

\section{DISCUSSION}

OMV vaccine candidates have been developed to control meningococcal disease outbreaks, but few vaccines have been licensed by regulatory agencies.

MenBvac (National Institute of Public Health, Norway) is a tailormade vaccine prepared from strain $B: 15: P 1.7,16$. The phase III controlled trial carried out in the 1990s demonstrated an efficacy of $57 \%$ in teenagers aged $14-16$ years. This vaccine was not widely used in the Norwegian and French outbreaks, and its effectiveness in these homologous contexts was not estimated.[1,31]

The vaccine MeNZB (Chiron, USA) was a vaccine specifically developed to control an epidemic produced by New Zealand strain $\mathrm{B}: 4: \mathrm{P} 1.7 \mathrm{~b}, 4$. No phase III clinical trials were undertaken; therefore, no direct estimate of efficacy was calculated. However, this tailormade vaccine was administered to $>100,000$ individuals aged 6 months to 19 years in 2004 and 2005, with vaccine effectiveness estimated at $73 \%$ by statistical modeling and $80 \%(\mathrm{Cl} 52 \%-92 \%)$ in an observational cohort study of children aged $<5$ years. $[1,31,32]$

VA-MENGOC-BC's effectiveness in homologous contexts has ranged from $80 \%$ to $100 \%$ in all age groups, higher than other OMV vaccines.[2,3,12,17] This is interesting, considering that efficacy was established in the phase III clinical trial under ideal circumstances, while effectiveness was evaluated under field conditions.

The effectiveness of MenBvac and MeNZB against heterologous serogroup B strains has not been sufficiently explored. However, VA-MENGOC-BC's effectiveness in heterologous contexts has been extensively studied in epidemiological research carried out in Brazil, Uruguay and Colombia.

It is noteworthy that the effectiveness of VA-MENGOC-BC in heterologous contexts was $>80 \%$ in individuals aged $>4$ years, $60 \%-80 \%$ in children aged $2-4$ years, and $50 \%-60 \%$ in younger children. However, results in Colombia suggest that effectiveness might be higher in preschool children and infants in heterologous contexts.[24,26]

The lowest effectiveness was found in Brazilian children aged $<2$ years, though it was usually $>50 \%$. On the other hand, estimates of effectiveness increased when based on mortality rates or clinically severe meningococcal disease.[22-25]

The lower protective effectiveness for children aged less than four years reported by Moraes could be due to the selective effect of analyzing only laboratory-confirmed cases. Exclusion of cases not confirmed by laboratory analysis decreased effectiveness estimates because it missed severe cases in nonvaccinated children who died before reaching the hospital. Vaccinated children who developed the disease had milder clinical presentations, allowing them to reach the hospital and undergo laboratory diagnosis.[21,25]

On the other hand, the lower effectiveness found by Moraes' study, compared with other Brazilian studies, was also apparently related to retrospective and prospective enrollment of cases to increase sample size, which may have biased results. Retrospective analysis estimated vaccine coverage at $5 \%$, but actual population coverage was $12 \%$; thus, data for the controls underestimated vaccine coverage. As a result, odds ratio increases because of the large number of unvaccinated control children (130) and the small number of vaccinated children (7), decreasing estimated effectiveness. For prospective analysis, estimated and actual coverage were $93 \%$ and $92 \%$ respectively, and effectiveness increased to $55 \%$.[21,25]

Higher effectiveness against heterologous strains in older age groups could be related to immune system maturation, but one must also consider increasing exposure to $\mathrm{Nm}$ through close contact with carriers at home or at school (and at workplaces in adults). In this situation, immune response could be greater because of a booster effect against shared OMV components. However, protection levels achieved in children aged less than four years should not be undervalued.

It should be noted that a two-dose immunization schedule with a six-to-eight-week interval was used, and other studies have demonstrated that three doses of OMV vaccines, similar to the VAMENGOC-BC protocol in Cuba, increase immunogenicity against heterologous strains, which could be necessary for children aged less than two years.[28,33]

Morley's study at the Imperial College School of Medicine in London showed VA-MENGOC-BC immunogenic against various strains of meningococcus $B$ in children aged less than one year, supporting the conclusion that the vaccine-induced immune response in this age group is not limited to the vaccine strain.[28]

Some researchers contend that changes in meningococcal epidemiology and isolate phenotypes should not be attributed solely to the vaccine, because meningococcal disease occurs in cycles typically associated with switches between different genotype lineages. $[1,4,6,7]$ However, no switches to hypervirulent lineages have been detected in $>25$ years of VA-MENGOC-BC application in Cuba.[18-20,34]

On the other hand, the Uruguayan study found that meningococcal disease incidence increased in unvaccinated age groups, while incidence was reduced significantly in the vaccinated age groups, regardless of whether outbreak strains were still circulating. [27] We therefore infer that changes in meningococcal disease epidemiology and carrier-state patterns in Cuba can be attributed to the vaccine, with sustained and massive vaccination campaigns essential to achieve these results.

Recently, other vaccines have been introduced on the market. Bexsero (GSK, UK) was developed by reverse vaccinology and contains the recombinant proteins $\mathrm{NadA}, \mathrm{fHbp}$ and NHBA, combined with OMVs of the New Zealand strain.[35,36] Trumemba (Pfizer, USA) is a recombinant vaccine containing fHbp A and B.[37] Both vaccines were designed to achieve broad crossreactivity. Phase II clinical trials have proven their immunogenicity, but controlled, randomized phase III clinical trials based on clinical endpoints have not been carried out and effectiveness has not yet been thoroughly assessed.[35-38] 
Bexsero was used by special FDA approval to control an outbreak of meningococcal disease at a US university in 2013. Immunogenicity was assessed by means of serum bactericidal antibody assay. Seropositivity, defined as an increase in serum bactericidal antibody titers of $>1: 4$, was $66 \%$, although no cases of meningococcal disease were reported among vaccinated students.[38] On the other hand, correlation between carriage and postvaccination serum bactericidal antibody titers has not been established.[39] Trumemba has been also used against university outbreak strains in the USA. Subjects with serum bactericidal antibody titers $>1: 4$ have ranged from $20 \%$ to $100 \%$.[37]

Despite the appearance of these new vaccines, VA-MENGOC$\mathrm{BC}$ should not be disregarded. This vaccine has proven high effectiveness not restricted to preventing meningococcal disease caused by homologous serogroup B strains. This leads us to suggest that it should also be considered an option in heterologous contexts.

No data on OMV immunogenicity are available in most postmarketing effectiveness studies. In any case, one must consider that the serum bactericidal antibody assay, gold standard for meningococcal polysaccharide vaccines, underestimates the protection elicited by VA-MENGOC-BC OMVs. In addition, the vaccine induces other protective mechanisms more important than antibody-dependent complement mediated lysis and should be factored in: T-cell mediated responses (Th1 pattern), stimulation of neutrophils and other phagocytic cells, antibody opsonophagocytosis, interference with bacterial metabolism, and mucosal immunity.[40]

The reactivity against heterologous serogroup $B$ strains induced by VA-MENGOC-BC could be due to deficiency in immunodominant proteins, in particular Por A, and a higher expression of crossreactive antigens identified on the vaccine's OMV. These include not only well-studied antigens, but also novel antigens that could be useful for developing a new generation of meningococcal vaccines.[13-15] On the other hand, although OMVs are deficient in Por A, they are sufficiently present for homologous bactericidal activity.

VA-MENGOC-BC's clinical effectiveness against $\mathrm{Nm}$ serogroup $C$ outbreaks has not been assessed, but the elevated levels of bactericidal antibodies it elicits indicate protection against this serogroup in all age groups, even infants. Furthermore, serogroup C strains have not been isolated in patients or carriers after the vaccine's massive application and inclusion in Cuba's PNI. These results support the serological effectiveness of the vaccine polysaccharide.[2,28-30]

The adequate immune response in children aged less than two years vaccinated with VA-MENGOC-BC, the absence of hyporesponsiveness after several doses of the vaccine, and the long-lasting immune response induced by the vaccine, support the thymus-dependent nature of the vaccine's C component. [28-30] On the other hand, the vesicles' adjuvant capability could considerably improve serogroup $\mathrm{C}$ polysaccharide immunogenicity, which should be considered for new combinations of the other meningococcal polysaccharides with OMVs.[40]

Finally, it is important to emphasize that modification of carrierstate patterns with reduction of hypervirulent lineages should be a consideration in designing vaccination strategies. The carrierstate pattern modification in vaccinated persons can interrupt the transmission chain, even protecting unvaccinated young children. This interesting strategy should be explored in greater depth.

\section{CONCLUSIONS}

In addition to prevention of meningococcal disease caused by homologous serogroup B strains, Cuba's VA-MENGOC-BC should be considered for heterologous contexts. It is protective against serogroup $\mathrm{C}$ in all age groups.

\section{ACKNOWLEDGMENTS}

The authors thank Mayelín Mirabal for support with statistical analysis. 1 -

\section{REFERENCES}

1. Oviedo-Orta E, Ahmed S, Rappuoli R, Black S. Prevention and control of meningococcal outbreaks: the emerging role of serogroup B meningococcal vaccines. Vaccine. $2015 \mathrm{Jul}$ 17;33(31):3628-35.

2. Sotolongo F, Campa C, Casanueva V, Fajardo EM, Cuevas IE, González N. Cuban meningococcal $B C$ vaccine: experiences \& contributions from 20 years of application. MEDICC Rev. 2007 Oct;9(1):16-22.

3. Ochoa RF, Sierra G. Vacunas contra la enfermedad meningocócica. In: Ochoa RF, Menéndez $\mathrm{J}$, editors. Prevención de la enfermedad meningocócica. 1st ed. Havana: Finlay Ediciones; 2010. p. 67-84. Spanish.

4. Borrow R, Lee JS, Vázquez JA, Enwere G, Taha $\mathrm{MK}$, Kamiya $\mathrm{H}$, et al. Meningococcal disease in the Asia-Pacific region: Findings and recommendations from the Global Meningococcal Initiative. Vaccine. 2016 Nov 21;34(48):5855-62.

5. Ahmed SS, Oviedo-Orta E, Mekaru SR, Freifeld CC, Tougas G, Brownstein JS. Surveillance for Neisseria meningitidis disease activity and transmission using information technology. PLoS One [Internet]. 2015 May 20 [cited 2017 Mar 24];10(5):e0127406. Available from: http:// dx.plos.org/10.1371/journal.pone.0127406
6. Jafri RZ, Ali A, Messonnier NE, Tevi-Benissan C, Durrheim D, Eskola J, et al. Global epidemiology of invasive meningococcal disease. Popul Health Metr [Internet]. 2013 Sep 10 [cited 2017 Mar 24];11(1):17. Available from: https://pophealthmetrics.biomedcentral.com/ articles/10.1186/1478-7954-11-17

7. Sridhar S, Greenwood B, Head Ch, Plotkin SA, Sáfadi MA, Saha $S$, et al. Global incidence of serogroup $B$ invasive meningococcal disease: a systematic review. Lancet Infect Dis. 2015 Nov;15(11):1334-46.

8. Bianchi A, Fantoni S, Prugnola A. Meningococcal $B$ vaccine and the vision of a meningitis free world. J Prev Med Hyg. 2015 Aug 31;56(3):E140-3.

9. McNeil LK, Zagursky RJ, Lin SL, Murphy E, Zlotnick GW, Hoiseth SK, et al. Role of factor $\mathrm{H}$ binding protein in Neisseria meningitidis virulence and its potential as a vaccine candidate to broadly protect against Meningococcal disease. Microbiol Mol Biol Rev. 2013 Jun;77(2):234-52

10. Vermont C, van den Dobbelsteen G. Neisseria meningitidis serogroup $\mathrm{B}$ : laboratory correlates of protection. FEMS Immunol Med Microbiol. 2002 Oct 11;34(2):89-96.
11. Centers for Disease Control and Prevention. Serogroup B meningococcal diseaseOregon, 1994. Morb Mortal Wkly Rep. 1995 Feb 24;44(7):121-4.

12. Sierra GV, Campa HC, Valcárcel NM, García IL, Izquierdo PL, Sotolongo PF, et al. Vaccine against group B Neisseria meningitidis: protection trial and mass vaccination results in Cuba. NIPH Ann. 1991 Dec;14(2):195-207.

13. Uli L, Castellanos-Serra L, Betancourt L, Domínguez $F$, Barberá $R$, Sotolongo $F$, et al. Outer membrane vesicles of the VAMENGOC-BC $\AA$ vaccine against serogroup $B$ of Neisseria meningitidis: Analysis of protein components by two-dimensional gel electrophoresis and mass spectrometry. Proteomics. 2006 Jun;6(11):3389-99.

14. Gil J, Betancourt LH, Sardiñas G, Yero D, Niebla O, Delgado $M$, et al. Proteomic study via a non-gel based approach of meningococcal outer membrane vesicle vaccine obtained from strain CU385: a road map for discovering new antigens. Hum Vaccine. 2009 May;5(5):347-56.

15. Williams JN, Weynants V, Poolman JT, Heckels JE, Christodoulides M. Immuno-proteomic analysis of human immune responses to experimental Neisseria meningitidis outer membrane vesicle 
vaccines identifies potential cross-reactive antigens. Vaccine. 2014 Mar 5;32(11):1280-6.

16. Orenstein WA, Bernier $\mathrm{RH}$, Hinman AR. Assessing vaccine effectiveness in the field. Further observations. Epidemiol Rev. 1988 Jan 1;10(1):212-41.

17. Pérez Rodríguez A, Dickinson Meneses F, Rodríguez Ortega M. Efectividad de la vacuna antimeningocócica VA-MENGOC-BC $®$ en el primer año de vida, Cuba, 1997-2008. Rev Cubana Med Trop. 2011 May-Aug;63(2):155-60. Spanish.

18. Martínez Motas I, Sierra González G, Núñez Gutiérrez N, Izquierdo Pérez L, Climent Ruiz $\mathrm{Y}$, Mirabal Sosa M. Caracterización de cepas de Neisseria meningitidis aisladas de portadores en Cuba durante 20 años. Rev Cubana Med Trop. 2006 May-Aug;58(2):124-33. Spanish.

19. Climent $Y$, Yero D, Martínez I, Martín A, Jolley KA, Sotolongo $F$, et al. Clonal distribution of diseaseassociated and healthy carrier isolates of Neisseria meningitidis between 1983 and 2005 in Cuba. J Clin Microbiol. 2010 Mar;48(3):802-10.

20. Climent $Y$, Urwin R, Yero D, Martínez I, Martín A, Sotolongo $\mathrm{F}$, et al. The genetic structure of Neisseria meningitidis populations in Cuba before and after the introduction of a serogroup BC vaccine. Infect Genet Evol. 2010 May;10(4):546-54.

21. de Moraes JC, Perkins BA, Camargo MC, Hidalgo NT, Barbosa HA, Sacchi CT, et al. Protective efficacy of a serogroup $B$ meningococcal vaccine in Sao Paulo, Brazil. Lancet. 1992 Oct 31;340(8827):1074-8.

22. Noronha CP, Struchiner CJ, Halloran ME. Assessment of the direct effectiveness of $B C$ meningococcal vaccine in Rio de Janeiro, Brazil: a case-control study. Int J Epidemiol. 1995 Oct:24(5):1050-7.

23. Costa $\mathrm{EA}$, Martins $\mathrm{H}$, Klein $\mathrm{CH}$. Avaliação da proteção conferida pela vacina antimeningocócica BC no Estado de Santa Catarina, Brazil, 1990/92. Rev Saúde Pública. 1996 Apr;30(5):460-70. Portuguese.

24. Galeano LA, Echeverry ML. Efectividad de una vacuna antimeningocóccica en una cohorte de Itaguí, Colombia, 1995. Bol Epidemiol Antioquia. 1995;20(2):110-8. Spanish.

25. Costa EA. On the Controversy about the effectiveness of the antimeningococcal $B$ vaccine: methodological pitfalls. Cad Saúde Pública. 1995 Apr-Jun;11(2):332-5.

26. Echeverry Uribe ML, Malberty Agüero JA, Galeano Marín LA, Sotolongo Padrón FT, Galguera Domínguez MA, Montoya Barrientos $\mathrm{CM}$, et al. Respuesta inmune humoral a las proteínas de una vacuna antimeningocócica $B C$ en un ensayo realizado en Antioquia, Colombia. Bol Oficina Sanit Panam. 1995 Apr;118(4):285-94. Spanish.
27. Pírez MC, Picón T, Galazka J, Rubio I, Montano A, Ferrari AM. Control de un brote epidémico de enfermedad meningocócica por Neisseria meningitidis serogrupo B. Rev Méd Urug. 2004 Aug;20(2):92-101. Spanish.

28. Morley SL, Cole MJ, Ison CA, Camaraza MA, Sotolongo $\mathrm{F}$, Anwar $\mathrm{N}$, et al. Immunogenicity of a serogroup $B$ meningococcal vaccine against multiple Neisseria meningitidis strains in infants. Pediatr Infect Dis J. 2001 Nov:20(11):1054-61.

29. Camaraza MA, Ochoa R, Arnet A, Sotolongo F, Martínez I, Cuevas I, et al. Inmunogenicidad inducida por la vacuna antimeningocócica VAMENGOC-BC $\otimes$ contra la cepa de $\mathrm{N}$ meningitidis ATCC C11 en adolescentes después de 12 años de vacunados. Rev Cubana Med Trop. 2004 Jan-Apr:56(1):26-30. Spanish.

30. Echeverry Uribe ML, Malberty Agüero JA, Galeano Marín LA, Sotolongo Padrón FT, Galguera MA, Montoya CM, et al. Respuesta inmune humoral al polisacárido capsular de Neisseria meningitidis serogrupo $C$ en un ensayo de vacunación antimeningocócica BC en Antioquia, Colombia. Bol Oficina Sanit Panam. 1995 Apr;118(4):295-301. Spanish.

31. Sadarangani M, Pollard AJ. Serogroup B meningococcal vaccines-an unfinished story. Lancet Infect Dis. 2010 Feb;10(2):112-24.

32. Galloway $\mathrm{Y}$, Stehr-Green $\mathrm{P}$, McNicholas A, O'Hallahan J. Use of an observational cohort study to estimate the effectiveness of the New Zealand group B meningococcal vaccines in children aged under 5 years. Int J Epidemiol. 2009 Apr;38(2):413-8.

33. Boutriau D, Poolman J, Borrow R, Findlow J, Diez-Domingo J, Puig-Barbera J, et al. Immunogenicity and safety of three doses of a bivalent (B:4:P1.19,15 and B:4:P1.7-2,4) meningococcal outer membrane vesicle vaccine in healthy adolescents. Clin Vaccine Immunol. 2007 Jan;14(1):65-73.

34. Biblioteca Virtual en Salud de Cuba [Internet]. Havana: Ministry of Public Health (CU); c2018. Anuario Estadístico de Cuba; [cited 2017 Feb 17]; [about 1 screen]. Available from: http:// bvscuba.sld.cu/anuario-estadistico-de-cuba/. Spanish.

35. Santolaya ME, O'Ryan ML, Valenzuela MT, Prado $V$, Vergara R, Muñoz A, et al. Immunogenicity and tolerability of a multicomponent meningococcal serogroup $B(4 \mathrm{CMenB})$ vaccine in healthy adolescents in Chile: a phase $2 \mathrm{~b} / 3$ randomised, observer-blind, placebo-controlled study. Lancet. 2012 Feb 18;379(9816):617-24.

36. Gossger N, Snape MD, Yu LM, Finn A, Bona G, Esposito $\mathrm{S}$, et al. Immunogenicity and tolerability of recombinant serogroup B Meningococcal vac- cine administered with or without routine infant vaccinations according to different immunization schedules: a randomized controlled trial. JAMA. 2012 Feb 8;307(6):573-82.

37. Donald RG, Hawkins JC, Hao L, Liberator $P$, Jones TR, Harris SL, et al. Meningococcal serogroup B vaccines: Estimating breadth of coverage. Hum Vaccin Immunother. 2017 Feb;13(2):255-65

38. Basta NE, Mahmoud AAF, Wolfson J, Ploss A Heller BL, Hanna S, et al. Immunogenicity of a meningococcal $B$ vaccine during a university outbreak. N Engl J Med. 2016 Jul 21;375(3):220-8.

39. Read RC, Dull P, Bai X, Nolan K, Findlow J, Bazaz R, et al. A phase III observer-blind randomized, controlled study to evaluate the immune response and the correlation with nasopharyngeal carriage after immunization of university students with a quadrivalent meningococcal ACWY glycoconjugate or serogroup B meningococcal vaccine. Vaccine. 2017 Jan 11;35(3):427-34.

40. Pérez O, Lastre M, Lapinet J, Bracho G, Díaz $\mathrm{M}$, Zayas $\mathrm{C}$, et al. Immune response induction and new effector mechanisms possibly involved in protection conferred by the Cuban anti-Meningococcal BC vaccine. Infect Immun. 2001 Jul:69(7):4502-8.

\section{THE AUTHORS}

Rolando F. Ochoa-Azze (Corresponding author: ochoa@finlay.edu.cu), immunologist with a doctorate in medical sciences. Full professor, Department of Immunology, Victoria de Girón Institute of Basic and Preclinical Sciences, Medical University of Havana; senior researcher, Finlay Vaccine Institute, Havana, Cuba.

Luis García-Imía, biochemist with a doctorate in health sciences. Senior researcher, Project Department, Finlay Vaccine Institute, Havana, Cuba.

Vicente Vérez-Bencomo, chemist with a doctorate in chemical sciences. Director General, Finlay Vaccine Institute, Havana, Cuba.

Submitted: November 15, 2017

Approved for publication: June 7, 2018

Disclosures: All authors are employees of the institute that developed VA-MENGOC-BC. 